\title{
Psychological factors related to musculoskeletal pain among Iranian female adolescents
}

Mohammad Aryaie $^{1^{*}}$, Zahra Khombehbini ${ }^{1}$, Fozieh Bakhsha ${ }^{2}$, Zahra Yousefi ${ }^{2}$, Omid Behravesh $^{2}$

1. Health Management and Social Development Research Center, Golestan University of Medical Sciences, Gorgan, Iran

2. Department of Anesthesiology, Faculty of Paramedical Sciences, Golestan University of Medical Science, Gorgan, Iran

*Corresponding author:Tel: +98 9112771798 Fax: +98 1732421655

Address: Deputy of research, Golestan University of medical science, Herkan blv begining of road Shastkola, Gorgan, Iran

E-mail: aryaie@goums.ac.ir

Received; 2016/01/29 revised; 2016/05/29 accepted; 2016/07/15

\section{Abstract}

Introduction: Musculoskeletal pain accompanied by psychological problem lead to reduce the efficiency of adolescents; so, this study aimed to determine the prevalence of musculoskeletal pain and its association with psychological factors among female adolescents.

Materials and methods: The target population of this cross sectional study was female students (3625 in total) from both private and state funded high school children in Gorgan, northern Iran. Self - assessment questionnaires were distributed to 255 students across 8 female high schools. Self-report version of the Strengths and Difficulties (SDQ) questionnaires was used to screen adolescents with Psychiatric symptoms. To evaluate musculoskeletal pain Nordic questionnaire and numeric pain rating scale was used. Data were analyzed by binary logistic regression and the cumulative odds ratio (COR) was carried out for the ordinal level of musculoskeletal symptoms.

Results: The prevalence rate of neck, shoulder and low back pain was reported, $23.1 \%$, $27.8 \%$ and $27.7 \%$, respectively. Hyperactivity-inattention (OR=2. 82; CI: 1.14-6.97) and peer problem $(\mathrm{OR}=2.72$; $\mathrm{CI}$ : 1.01-7.32) had significant relationship with neck pain, and prosocial behaviors $(\mathrm{OR}=3.11$; CI: $1.09-10.73)$ were associated with low back pain in the multivariate model. Ordinal regression showed that the increasing numbers of musculoskeletal symptoms related only to prosocial behavior $(\mathrm{COR}=2.78$; $\mathrm{CI}$ : 1.12-6.91). There was no significant association between shoulder pain and psychological factors.

Conclusion: Based on the results, psychological factors were associated with musculoskeletal pain; so, it seems suffering from musculoskeletal pain need to be concurrently noticed with mental feeling for more effective response to attenuate pain.

Keywords: Psychological problems, Neck, Shoulder, Low back pain

\section{Introduction}

Neck, shoulder and low back pain have been indicated as widespread difficulties in many countries (1-4), and it is reported that pain interfered with patients daily activities (5). Pain is a very common condition which coexists with a variety of neuropsychiatric disorders that have profoundly places a heavy burden on patients accompanied by high social cost $(6,7)$. Studies have shown that the prevalence of neck, shoulder and low back pain is considerable in adolescents, especially in girls (8-10). In addition, the prevalence range of psychological disorders was reported approximately 
between 11 to 18 percent among this age group $(11,12)$.

Mental stress has been identified to be related to musculoskeletal diseases with a greater proportion of girls compared to boys (13-15). In spite of this, lower pain threshold in girls than boys $(16,17)$, higher susceptibility to pain (18), and special hormonal changes apparent around puberty (19) might be the reasons for being more prone to the occurrence of pain in girls. The occurrence of shoulder, neck and low back pain in five districts of Tehran, the capital city of Iran, were reported $18.46,13.42$ and 8.5 , respectively (20) and overall rate of psychiatric disorders, including, emotional, conduct, hyperactivity, problems with peer and social problems, was 14.6 percent in five cities of Iran (3).

Mohammadi et al reported more prevalent psychiatric symptoms in high schools compared to middle schools with a higher rate in girls, in Iran (3). Mental and behavioral disorders (ranked second) and also low back pain (ranked sixth) are placed among top twenty diseases, according to a DALY index in Iranian female, whereas, male were ranked in lower ranks compared to their opposite sex (21).

Although the epidemiological survey has provided a perspective on prevalence rate and risk factors of psychiatric difficulties $(3,22)$, the association between mental problems and musculoskeletal disorders is rarely investigated in Iran, exclusively in adolescent. So, this study was aimed to investigate the relationship between prevalence of pain in the neck- shoulder and low back region and psychological status among female high school students in northern region of Iran. We also evaluated the association between the increase numbers of musculoskeletal symptoms and mental difficulties.

\section{Materials and methods}

Participants and collecting data: Data were collected in Gorgan, northern region of Iran (23), from November to March, 2013. The target population of this cross sectional study was female students (3625 in total) from both private and state funded high school children grade, 9th (15-16 years) to12th (16-17 years). Among all of 34 female high schools, eight of them were selected by utilizing multistep cluster sampling approach which 255 students participate in the present study. Mentally retarded or handicapped and subjects who had pain due to accident were considered as an exclusion criteria.This research was approved by the school authorities and the ethics committee of Golestan University of medical science. Questionnaires were offered by teacher during an appropriate school time and were taken in a sealed envelope .

Musculoskeletal questionnaire: To evaluate musculoskeletal pain, including neck, shoulder and low back pain in a target population, Standardied Nordic Questionnaires and Numeric Pain Rating Scale, which answers were dichotomized into two groups, were used.

Psychological questionnaire: Self-report version of the Strengths and Difficulties Questionnaire (SDQ), was used to screen adolescents with Psychiatric symptoms. The Iranian version of the SDQ, with a Cronbach's alpha coefficient of 0.74 , has been confirmed to be applicable to adolescents (24). Mental status was evaluated by SDQ include 25 selfassessment questions to measure five scales (scoring 0-1-2): hyperactivityinattention, emotional symptoms, conduct problem, peer problem, and prosocial behavior scales. Students with somatic symptoms were excluded before performing the statistical analysis. In the emotional symptom scale was excluded. Cut off points of $90 \%$ were used to determine students with a Psychiatric symptoms who were placed among the highest $10 \%$ (the lowest $10 \%$ were considered for prosocial scale). 


\section{Statistical analysis}

The association between neck/ shoulder, low back pain and psychological status were analyzed using univariate logistic regression. The number of Musculoskeletal symptoms was combined together and categorized as none, one, two and three symptoms, and the cumulative odds ratio was carried out to estimate the relationship between Psychosocial and numbers of musculoskeletal symptoms (the ordinal level of symptoms from having one musculoskeletal symptom to three of them). Significant variables at level 0.1 in unadjusted models were considered for the multivariate model. SPSS version 16.0 (SPSS Inc., Chicago, IL, USA) was used for the statistical analysis. $\mathrm{P}$ value less than 0.05 was considered as significant.

\section{Results}

Two hundred fifty five female high school students with the mean age of 15 participated in this research. The rate of answering to the questionnaire was 78 percent and nine students were excluded due to somatic symptoms.
Prevalence of musculoskeletal pain and psychological problems: The twenty third of participants had neck pain, $27.8 \%$ shoulder pain and it was reported $27.7 \%$ for low back pain. The occurrence of psychological problems, including emotional, hyperactivity-inattention, conduct, peer and prosocial behavior problems were estimated $12.2 \%, 13.7 \%$, $18.4 \%, 10.2 \%$ and $9.8 \%$, respectively.

All dimensions of psychological difficulties except prosocial problems were significantly related to the neck pain in the univariate logistic regression model (Table 1). Among these factors, hyperactivityinattention $(\mathrm{OR}=2$. 82; CI: 1.14-6.97) and peer problem $(\mathrm{OR}=2.72$; CI: 1.01-7.32) remained significant in the multivariate logistic regression model. Prosocial behavior was also associated with low back pain in the final model $(\mathrm{OR}=3.11$; CI: 1.09-10.73). There was no significant association was found between shoulder pain and psychological factors and ordinal regression showed that the increasing numbers of musculoskeletal symptoms related only to prosocial behavior $(\mathrm{OR}=$ 2.78; CI: 1.12-6.91).

Table1. The relationship between psychological variables and having musculoskeletal pain according to univariate binary logistic regression and $95 \%$ confidence interval.

\begin{tabular}{|c|c|c|c|}
\hline Variable & $\begin{array}{c}\text { Neck } \\
\text { OR }(95 \% \mathrm{CI})\end{array}$ & $\begin{array}{c}\text { Shoulder } \\
\text { OR(95\%CI) }\end{array}$ & $\begin{array}{l}\text { Low back } \\
\text { OR( } 95 \% \text { CI })\end{array}$ \\
\hline $\begin{array}{l}\text { Emotional status } \\
\geq 90 \% /<90 \%\end{array}$ & $1.91(0.85-4.29)^{*}$ & $1.68(0.76 .3 .71)$ & $1.52(0.68 .3 .37)$ \\
\hline $\begin{array}{l}\text { Hyperactivity-inattention } \\
\geq 90 \% /<90 \%\end{array}$ & $2.06(0.94-4.51)^{*}$ & $1.27(0.58-2.77)$ & $1.53(0.71-3.31)$ \\
\hline $\begin{array}{l}\text { Conduct } \\
\geq 90 \% /<90 \%\end{array}$ & $1.99(0.99-4.03)^{*}$ & $1.62(0.82-3.19)$ & $1.09(0.54-2.21)$ \\
\hline $\begin{array}{l}\text { Peer problem } \\
\geq 90 \% /<90 \%\end{array}$ & $2.09(0.86-5.12)^{*}$ & $0.74(0.28-1.94)$ & $1.03(0.41-2.62)$ \\
\hline $\begin{array}{l}\text { Prosocial behavior } \\
\leq 100 />10 \%\end{array}$ & $1.28(0.46-3.59)$ & $1.74(0.63-4.85)$ & $3.11(1.09-10.73)^{*}$ \\
\hline
\end{tabular}

OR: Odds Ratio, CI: Confidence Intervals.

$* \mathrm{P}<0.05$. 


\section{Discussion}

The main findings of this study were the association between hyperactivityintention and peer problem with neck pain. Prosocial behavior difficulties were associated with low back pain and also with the increase number of musculoskeletal pain.

Psychological problems highly presented among adolescent $(25,26)$ and overlap with suffering pain (27). MS pain also present in the multiple body area and widely distributed in this population $(25$, $26,28)$ which seems to be significantly associated with the level of mental health problems $(29,30)$ that changing in psychological process has been advised $(31,32)$ for both early and late treatment due to the complexity of determining timing change and reducing a variety of pain which is difficult to separate from musculoskeletal pain $(33,34)$. Moreover, the co-occurrence of MS pain and psychological problems might be associated through a shared neurobiological pathway (35).

We found stronger association between psychological problems with neck pain compared to shoulder and low back pain. Some researchers suggest that considering items from both areas concurrently would be more beneficial, due to being difficult to express emotional and physiological pain separately $(36,37)$. Considering the lower prevalence of psychiatric difficulties than pain in the current study, might be concluded that pain lead to psychological problems; but Shan and colleagues concluded that due to positive effects of psychological treatment on the musculoskeletal pain, depressive feelings would be more likely to be causes rather than the result of musculoskeletal pain (6). Siivola also detected that psychological symptoms predicted neck and shoulder pain in subjects who were had no musculoskeletal sign at baseline (38). The association between psychological problem and the occurrence of musculoskeletal disease has been also revealed in some other studies $(39,40)$. Our study showed there were no relation between emotional and conduct problems with prevalence of neck and low back pain; whereas, the significant association between point prevalence of low back pain and two aforementioned psychological problems has been shown in Watson study (37). Contrary to our findings, there were no significant relationship between prosocial behavior and LBP in Watson survey (37). One might be argue is that consider adolescent in early age between 11-14 years old, whereas; the age of students in the present survey was between 15-17 years old.

Our survey found a stronger relationship between neck pain and mental health difficulties than low back pain. In contrast to our survey, Shan and colleagues detected a significant higher depression score with low back pain compared to neck pain. They stated the reason might be that student more willing to lessen the neck pain, especially those who have more psychiatric symptoms (6). The association between neck pain and stress and depress feeling found more often among some ethnicity in the study of Diepenmeat which is in line with the current research.Some participant in our study was also from different ethnicity like Turkmen and Sistanior non-persian.

The occurrence of low back pain was more prevalent compared to neck pain in our research which is in contrast with the studies conducted by Murphy and colleagues $(37,41)$. The difference might be associated to the populations under study. On the other hand, it has been expressed more prevalent of pain in the range of 12-14 (42), whereas students who participate in our study were between 1517 years old. However, some research has revealed that the higher prevalence of MS pains and psychological pressure are along with the increase of the high school 
students' grade $(6,25)$. This conclusion might be related to leading the sedentary life caused by the heavy burden of academic course and being in the incorrect posture to study long hours for the college entrance exams in China, however; no association between musculoskeletal pain and the level of activity was detected in this survey(6), the same situation exists for Iranian students. Helmus and colleague (43) also mentioned that the level of activity of patient suffering chronic musculoskeletal pain unrelated to psychological factor. The prevalence of low back pain in our study is higher than Shan (6) survey but is lower than Diepenmeat research (13). The result in our study may overestimated, because it seems student with pain are more willing to response the questions; however, Diepenmeat (13) and collegueas, showed there were no difference in the occurrence of pain between respondent and nonrespondent subjects.

The occurrence of neck and shoulder pain was 23.1 and $27.8 \%$ respectively. These findings are significantly higher than those with a research were conducted by Shan and colleague, the prevalence of neck and shoulder pain was both $40.8 \%$, on adolescent (6). This divergence may be correlated to considering heavy academic rule on high school pupil's posture in china.

In the current study, there was no association between mental health problem and prevalence of shoulder pain. A study was conducted by Badcock and colleague (44) identified the correlation of pain and

\section{References}

1. Astfalck RG, O'Sullivan PB, Straker LM, Smith AJ. A detailed characterisation of pain, disability, physical and psychological features of a small group of adolescents with nonspecific chronic low back pain. Man Ther. 2010 Jun;15(3):240-7.

2. E-Metwally A, Salminen JJ, Auvinen A, Macfarlane G, Mikkelsson M. Risk mental health relevant to the level of disability, whereas; disability was not considered in the present study.

Strength and limitation: The main strength of the present study is the use of cumulative odds ratio to evaluate the level of musculoskeletal pain as the probability of being key drivers of psychiatric problems. Self-reporting has been introduced as a 'gold standard' for evaluating pain in epidemiological studies even thought, recall bias and assessing the pain duration may have affected the finding (25). In addition, a small number of subjects for calculating the cumulative odds ratio in the present study need to be noticed as our study limitation. The casualty association in the current research is less sufficient by its cross- sectional design.

\section{Conclusion}

According to thefindings, psychological factors, including hyperactivity-inattention and peer problem associated with neck pain, and prosocial behavior related with the low back pain and the increase number of musculoskeletal pain; so, it seems suffering from the musculoskeletal pain need to be concurrently noticed with mental feeling for more effective response in attenuate pain.

\section{Acknowledgements}

We thank the students and Golestan University of Medical Science of their valuable contribution in this research.

factors for development of non-specific musculoskeletal pain in preteens and early adolescents: a prospective 1-year follow-up study. BMC Musculoskelet Disord. 2007;8(1):46.

3. Mohammadi MR, Arman S, Dastjerdi JK, Salmanian M, Ahmadi N, Ghanizadeh A, et al. Psychological Problems in Iranian Adolescents: 
Application of the Self Report Form of Strengths and Difficulties Questionnaire. Iran J Psychiatry. 2013; 8(4):152-9.

4. Yao W, Luo C, Ai F, Chen Q. Risk Factors for Nonspecific Low-Back Pain in Chinese Adolescents: A Case-Control Study. Pain Med. 2012; 13(5):658-64.

5. Nieto $\mathrm{Rn}$, Raichle $\mathrm{KA}$, Jensen MP, Miro J. Changes in pain-related beliefs, coping, and catastrophizing predict changes in pain intensity, pain interference, and psychological functioning in individuals with myotonic muscular dystrophy and facioscapulohumeral dystrophy. Clin J Pain. 2012; 28(1):47-54.

6. Shan Z, Deng G, Li J, Li Y, Zhang Y, Zhao Q. Correlational Analysis of neck/shoulder Pain and Low Back Pain with the Use of Digital Products, Physical Activity and Psychological Status among Adolescents in Shanghai. PloS One. 2013;8(10):e78109.

7. Spyropoulos P, Papathanasiou G, Georgoudis G, Chronopoulos E, Koutis H, Koumoutsou F. Prevalence of low back pain in Greek public office workers. Pain Physic. 2007;10(5):651.

8. Auvinen JP, Tammelin TH, Taimela SP, Zitting PJ, Jarvelin M-R, Taanila $\mathrm{AM}$, et al. Is insufficient quantity and quality of sleep a risk factor for neck, shoulder and low back pain? A longitudinal study among adolescents. Eur Spine J. 2010; 19(4):641-9.

9. Pollock CM, Harries RL, Smith AJ, Straker LM, Kendall GE, Sullivan PB. Neck/shoulder pain is more strongly related to depressed mood in adolescent girls than in boys. Man Ther. 2011 Jun;16(3):246-51.

10. Gunilla M, Sundblad B, Saartok Tn, T. Engstrom. Prevalence and cooccurrence of self-rated pain and perceived health in school-children: Age and gender differences. Eur $\mathbf{J}$ Pain. 2007;11(2):171-80.
11. Costello EJ, Mustillo S, Erkanli A, Keeler G, Angold A. Prevalence and development of psychiatric disorders in childhood and adolescence. Arch Gen Psychiatry. 2003; 60(8):837-44.

12. Sawyer MG, Arney FM, Baghurst PA, Clark JJ, Graetz BW, Kosky RJ, et al. The mental health of young people in Australia: key findings from the child and adolescent component of the national survey of mental health and well-being. Aust N Z J Psychiatry. 2001;35(6):806-14.

13. Diepenmaat A, Van der Wal M, De Vet H, Hirasing R. Neck/shoulder, low back, and arm pain in relation to computer use, physical activity, stress, and depression among Dutch adolescents. Pediatrics. 2006;117(2):412-6.

14. Harma A-M, Kaltiala-Heino R, Rimpela M, Rantanen P. Are adolescents with frequent pain symptoms more depressed? Scand J Prim Health Care. 2002;20(2):92-6.

15. Mikkelsson M, Sourander A, Piha J, Salminen JJ. Psychiatric symptoms in preadolescents with musculoskeletal pain and fibromyalgia. Pediatrics. 1997; 100(2):220-7.

16. Chiu TT, Lam T-H, Hedley AJ. Maximal isometric muscle strength of the cervical spine in healthy volunteers. Clin Rehabil. 2002;16(7):772-9.

17. Torgen M, Swerup C. Individual factors and physical work load in relation to sensory thresholds in a middle-aged general population sample. Eur J Appl Physiol. 2002; 86(5):418-27.

18. Wijnhoven HAH, de Vet HCW, Picavet HSJ. Explaining sex differences in chronic musculoskeletal pain in a general population. Pain. 2006; 124(1):158-66.

19. Wedderkopp N, Andersen LB, Froberg $\mathrm{K}$, Leboeuf-Yde C. Back pain reporting in young girls appears to be 
puberty-related. BMC Musculoskelet Disord. 2005;6(1):52.

20. Shamsedini A, Hellisaz MT, Dalvand $\mathrm{H}$, Khatibi A, Sobhani V. The investigation of prevalence of musculoskeletal symptoms and discomfort caused by them in students of Tehran. HBI J. 2011;8(4):271-6.

21. Naghavi M, Abolhassani F, Pourmalek F, Lakeh MM, Jafari N, Vaseghi S, et al. The burden of disease and injury in Iran 2003. Popul Health Metr. 2009;7(1):9.

22. Shahrivar Z, Tehrani-Doost M, Pakbaz B, Rezaie A, Ahmadi F. Normative data and psychometric properties of the parent and teacher versions of the strengths and difficulties questionnaire (SDQ) in an Iranian community sample. J Res Med Sci. 2009;14(2):69-77.

23. Aryaie M, Roshandel G, Semnani S, Asadi-Lari M, Aarabi M, Vakili MA, et al. Predictors of Colorectal Cancer Survival in Golestan, Iran: A Population-based Study. Epidemiol Health. 2013;35:e2013004.

24. Ghanizadeh A, Izadpanah A, Abdollahi G. Scale validation of the strengths and difficulties questionnaire in Iranian children. Iran J Physic. 2007; (2):6571.

25. Jussila L, Paananen M, Nayha S, Taimela S, Tammelin T, Auvinen J, et al. Psychosocial and lifestyle correlates of musculoskeletal pain patterns in adolescence: A 2 year followo up study. Eur J Pain. 2014;18(1):139-46.

26. Rees CS, Smith AJ, O'Sullivan PB, Kendall GE, Straker LM. Back and neck pain are related to mental health problems in adolescence. BMC Public Health. 2011;11(1):382.

27. Bruusgaard D, Smedbraten BK, Natvig B. Bodily pain, sleep problems and mental distress in schoolchildren. Acta Paediatrica. 2000;89(5):598-600.

28. Jones GT, Silman AJ, Macfarlane GJ. Predicting the onset of widespread body pain among children. Arthritis Rheum. 2003;48(9):2615-21.

29. Larsson B, Sund AM. Emotional/behavioural, social correlates and one year predictors of frequent pains among early adolescents: Influences of pain characteristics. Eur J Pain. 2007;11(1):57-65.

30. Stanford EA, Chambers CT, Biesanz JC, Chen E. The frequency, trajectories and predictors of adolescent recurrent pain: a population-based approach. Pain. 2008;138(1):11-21.

31. Bergbom S, Boersma K, Linton SJ. Both early and late changes in psychological variables relate to treatment outcome for musculoskeletal pain patients at risk for disability. Behav Res Therap. 2012;50(11):72634.

32. Sullivan MJL, Adams H, Thibault P, Corbire M, Stanish WD. Initial depression severity and the trajectory of recovery following cognitivebehavioral intervention for work disability. J Occup Rehabil. 2006;16(1):60-71.

33. Speckens AE, Van Hemert AM, Spinhoven P, Hawton KE, Bolk JH, Rooijmans HG. Cognitive behavioural therapy for medically unexplained physical symptoms: a randomised controlled trial. BMJ. 1995;311(7016):1328-32.

34. Williams C, Wilson $\mathrm{P}$, Morrison $\mathrm{J}$, McMahon A, Andrew W, Allan L, et al. Guided self-help cognitive behavioural therapy for depression in primary care: a randomised controlled trial. PloS One. 2013; 8(1):e52735.

35. Nielsen LA, Henriksson KG. Pathophysiological mechanisms in chronic musculoskeletal pain (fibromyalgia): the role of central and peripheral sensitization and pain disinhibition. Best Pract Res Clin Rheumatol. 2007; 21(3):465-80. 
36. Balagu F, Dudler J, Nordin M. Lowback pain in children. Lancet. 2003;361(9367):1403-4.

37. Watson KD, Papageorgiou AC, Jones GT, Taylor S, Symmons DPM, Silman $\mathrm{AJ}$, et al. Low back pain in schoolchildren: the role of mechanical and psychosocial factors. Arch Dis Child. 2003;88(1):12-7.

38. Siivola SM, Levoska S, Latvala K, Hoskio E, Vanharanta H, KeinanenKiukaanniemi S. Predictive factors for neck and shoulder pain: a longitudinal study in young adults. Spine. 2004; 29(15):1662-9.

39. Roh YH, Noh JH, Oh JH, Baek GH, Gong HS. To what degree do shoulder outcome instruments reflect patients' psychologic distress? Clin Orthop Relat Res. 2012;470(12):3470-7.

40. Roh YH, Lee BK, Noh JH, Oh JH, Gong HS, Baek GH. Effect of depressive symptoms on perceived disability in patients with chronic shoulder pain. Arch Orthop Trauma Surg. 2012; 132(9):1251-7.
41. Murphy S, Buckle P, Stubbs D. A cross-sectional study of self-reported back and neck pain among English schoolchildren and associated physical and psychological risk factors. Appl Ergon. 2007;38(6):797-804.

42. O'Sullivan PB, Straker LM, Smith A, Perry M, Kendall G. Carer experience of back pain is associated with adolescent back pain experience even when controlling for other carer and family factors. Clin J Pain. 2008; 24(3):226-31.

43. Helmus M, Schiphorst Preuper HR, Hof AL, Geertzen JHB, Reneman MF. Psychological factors unrelated to activity level in patients with chronic musculoskeletal pain. Eur $\mathrm{J}$ Pain. 2011;16(8):1158-65.

44. Badcock LJ, Lewis M, Hay EM, McCarney R, Croft PR. Chronic shoulder pain in the community: a syndrome of disability or distress? Ann Rheum Dis. 2002;61(2):128-31. 